\title{
Operaciones de crédito
}

II.-Operactones det Banco de Crédito local de España

Fundamentalmente, el Banco de Crédito Local de España concierta con las entidades de Administración Local dos clases d operaciones financieras: el préstamo a largo plazo y los anticipos de tesorería u operaciones a plazo corto.

Se definen como entidades facultadas para el concierto de estag operaciones, los Ayuntamientos, last Diputaciones, las 'Agrupaciones forzosas de Municipios, las Mancomunidades de Ayuntamientos, las Mancomunidades Sanitarias provinciales y los Institutos provinciales de Sanidad. Estos dos últimos organismos fueron declarados locales, y por tanto, facultados para concertar operaciones financieras con el Banco, a virtud de Ordenes del Ministerio de la Gobernación de 3 de marzo y 24 de mayo de 1943, si bien condicionando las operaciones con los Institutos provinciales de Sanidad, a que su concierto se lleve a cabo por medio de Jas respectivas Mancomunidades sanitarias.

Las operaciones a largo plazo están constituídas por los préstamos simples y por los préstamos con previa apertura de cuenta de crédito; las de plazo corto están formadas por las cperaciones llamadas de tesorería, que atenderán desniveles monetarios transitorios de los presupuestos ordinarios o de los extraordinarios.

Las operaciones a largo plazo están reguladas actualmente por el Ministerio de Hacienda, organismo que ha dado a la publicidad los modelos de contratos que regirán para las mismas, por Orden de $10^{\circ}$ de agosto de 1945. 
a) Préstamos con previa apertura de cuenta de crédito.-El Banco de Crédito Local de España, de acuerdo con !as Corporaciones contratantes y teniendo en cuenta el plazo de desarroIlo del presupuesto extraordinario, abrirá provisionalmente un crédito para atender a las obligaciones derivadas del contrato. El plazo de duración del mismo podrá fijarse en uno, dos o más años, según las circunstancias al finalizar los cuales o antes si se hubiesen agotado los fondos o terminado las obras, quedará fijada la cifra definitiva que, como préstamo consolidará y con arreglo a cuya cuantía se formará el cuadro de amortización, que no tendrá plazo superior a cincuenta o treinta años., según lá índole de las obras o servicios emprendidos.

El contrato podrá abrir un crédito de cantidad determinada, ampliable a otra superior, cuando la Corporación contratante no tenga capacidad suficiente para encajar la anualidad resultante del préstamo. Limitado el crédito a la cantidad posible, se diferirá la contratación de la parte restante hasta que las liquidaciones posteriores aseguren una recaudación mayor; otras veces, estas ampliaciones se prevén para sincronizar el crédito disponible con el plan de ejecución de las obras; en otros casos, en fin, estas ampliaciones cubren el posible riesgo de que no sean concedidas las subvenciones o aportaciones pedidas.

La cuenta de crédito, que precede a la fijación de la cantidad que en definitiva consolidara como préstamo, se liquidará cada trimestre, a efectos del reembolso de los intereses sobre los saldos deudores y pago de la comisión bancaria, o de su acumulación a la cuenta, si este último aspecto hubiese sido 1'revisto mediante cláusula adicional al contrato.

Las ampliaciones de crédito, previstas en el contrato, se efectuarán de manera automática, una vez acredite la Corporación los requisitos exigidos para ello, extremo que se hará constar asimismo en la cláusula adicional al contrato.

b) Préstamo.-En las operaciones de préstamo no hay como en el caso anterior el plazo o período de consolidación que caracteriza los créditos. La cifra definitiva de préstamo se marca en el contrato y esta cantidad es la que puede utilizar la Corporación. 
Respecto del préstamo con previa apertura de cuenta de crédito tiene diferencias muy acusadas que conviene señalar.

El interés en los préstamos con apertura de cuenta de crédito va tomándose sobre los saldos deudores que presenta la cuenta provisional, interés que irá aumentando hasta llegar al que corresponde a la disposición total de fondos; luego en el período de consolidación los intereses satisfechos serán inferiores a los que devengue el préstamo.

El préstamo con apertura de crédito no presupone la cifra que en definitiva consolidara como deuda de la Corporación al Banco; el límite del crédito aparecerá determinado pero no la cifra definitiva que alcancen las disposiciones de fondos: con cargo a la misma, mientras que en el préstamo el volumen de la operación se conoce desde el primer momento.

El préstamo simple devengará interés a favor de la Corporación por las cantidades que no retire de la cuenta corriente a qua se abona, interés que se liquidará semestralmente y que no será inferior al máximo que fije o pueda fijar en lo sucesivo el Ministerio de Hacienda para las cuentas corrientes bancarias a la vista o a plazo, en tanto que el préstamo con apertura de cuenta de crédito no devenga en ningún momento intereses a favor de la Corporación.

El plazo de duración de los préstamosı simples será como mínimo de cincuenta o de treinta años, según los casos, mientras que en el préstamo con apertura de crédito, estos plazos máximos irán precedidos del plazo de conso idación del crédito, con lo cual siempre será mayor el tiempo de la operación.

En el mismo día en que se formalice el contrato, el Banco abonará en cuenta corriente a favor de la Corporación la cantidad importe del préstamo, con cargo a la cual se abonarán las peticiones de fondos mediante oficios suscritos por el Presidente con la toma de razón de los señores. Interventor y Depositario, debiendo acompañarse en cada caso de las certificaciones de obras que expida el Director técnico o las de adquisiciones o expropiaciones aprobadas con arreglo a' lo previsto en el artículo 92 del Reglamento de Hacienda Municipal.

Desde el momento de la firma de la operación nace la obli- 
gación para la Corporación Local, de ir abonando las anualidades de interés y amortización del préstamo.

c) Operaciones de tesoreria sobre presupuestos ordinarios.Son las operaciones de tesorería clásicas concertadas para atender el déficit momentáneo de dinero, que en cualquier época del ejercicio económico puede producirse, bien por el retraso en el cobro de recursos, ya por el avance en la contracción y pago de las obligaciones.

Según la legislación vigente, esta situación puede atenderse librando letras de cambio o expidiendo pagarés a la orden con vencimiento no superior a noventa dias contra la Caja de la Corporación, o mediante la apertura de una cuenta de crédito. El importe de las letras o pagarés, o el de la cuenta de crédito, no podrá exceder de la sexta parte del presupuesto o del 50 por 100 del importe del servicio, debiendo quedar recogidos estos efectos a su vencimiento o saldada la cuenta por trimestres con sus intereses y otros; devengos.

La libranza de letras de cambio o pagarés para aplicar su importe a déficits de tesorería, está limitada a las Corporaciones cuyo presupuesto ordinario exceda de dos millonesi de pesetas y a los que sin llegar a esta cifra, tengan en curso algún presupuesto extraordinario superior a quinientas mil pesetas. Aquellası Corporaciones que no reunen alguno de los requisitos que acaban de mencionarse, no podrán hacer uso de esta forma de crédito y deberán solventar sus dificultades transitorias de dinero por medio del concierto de una operación de crédito al plazo máximo de tres meses.

El Banco de Crédito Local de España abre cuentas de crédito a las Corporaciones peticionarias al' amparo de lo dispuesto en el apartado b) del artículo 334 del Decreto de 25 de enero de 1946, con las limitaciones establecidas en el mismo, referentes a plazo de la operación y cuantía del servicio.

Para ello se requiere el acuerdo del Pleno de la Corporación con el informe previo del Interventor o Secretario-Inteventor que dictaminará sobre las cláusulas del contrato de tesorería sometido a su conocimiento. Estos contratos estarán garantizados por la recaudación de los recursos que se convengan, de los 
cuales se hará ingreso en 'el establecimiento bancario que se determine. Las peticiones de fondos en descubierto contra la cuenta de tesorería, serán atendidas por el Banco hasta el límite fijado para la operación. Los saldos acreedores que presente la cuenta, que serán de libre disposición, devengarán el interés establecido para las cuentas corrientes a la vista. Los saldos deudores devengarán el interés previsto en el contrato, o el que para lo sucesivo devenguen las cédulas de contrapartida del préstamo.

E1 Decreto de 25 de enero de 1946 , dictado por el Ministerio de Hacienda, ha dispuesto que los créditos de Tesorería que se concierten para anticipos de cantidades procedentes de liquidaciones de Hacienda, intereses de Deuda del Estado, auxilios, subvenciones o reintegros a cargo del Tesoro, y en general, toda clase de ingresos que perciban por medio de las Delegaciones de Hacienda, podrán ser cancelados en plazo superior a seis meses al hacer efectivas las citadas cantidades.

El crédito máximo que con arreglo a esta disposición concederá el Banco de Crédito Local, no será superior al 50 por 100 del saldo líquido o resultante a favor de la Corporación por los conceptos que haya de percibir del Estado, deducidas las cantidades que el Tesoro tenga derecho a retener para compensar los créditos que ostente contra la Corporación, cualquiera que sea la naturaleza de éstos. Cuando el anticipo tenga por finalidad cubrir atenciones de personal, cargas financieras $u$ otras obligaciones de carácter preferente, podrá elevarse el límite del mismo al $\mathbf{7 5}$ por $\mathbf{1 0 0}$ del saldo líquido indicado.

d) Operaciones de Tesoreria sobre presupuestos extraordinarios.-Podrá el Banco efectuar estas operaciones en alguna de las dos formas que han quedado mencionadas en el apartado anterior; es decir, con estricta sujeción a lo dispuesto en el artículo 334, letra b), del Decreto de 25 de enero de 1946 sobre Ordenación Provisional de las Haciendas. Locales, o bien con arreglo a lo establecido en el Decreto de 25 de enero de $\mathbf{1 9 4 6}$, en cuyo texto estas operaciones se amplían por todo el tiempo que se tarde en percibir los ingresos o recursos que el Estado haya de liquidar. 
El presupuesto extraordinario podrá llevar aparejada la operación de crédito a largo plazo y necesitar, sin embargo, de una operación a corto plazo para su desarrollo. Tal es el caso en que se consignen subvenciones que el Estado no pueda iquidar en el plazo previsto o cuando la ejecución del presupuesto vaya escalonada con arreglo o un orden determinado en la percepción de ingresos.

El movimiento de la operación, tanto si se efectúa al amparo del artículo 334 citado, como si se hace por el Decreto de 25 de enero de 1946, es la misma que se ha señalado para las operaciones de tesorería sobre presupuestos ordinarios y no tienen en cuanto a ellas, otra diferencia que la de necesitar la autorización del Ministerio de Hacienda el proyecto de contrato que se estipule entre el Banco y la Corporación.

e) Servicio y operación conjuntos de tesoreria.-Como anejo al contrato principal, ya que sea éste de préstamo o de préstamo con previa apertura de cuenta de crédito, autoriza la Orden de 1 de agosto de 1945, dictada por el Ministerio de $\mathrm{Ha}$ cienda, el modelo de Convenio Adicional de Tesorería, cuya finalidad será facilitar la ejecución de los presupuestos extraordinarios y garantizar a la vez el cumplimiento de los compromisos contraídos. Encierra este contrato un servicio de tesorería y una operación de igual naturaleza.

El servicio tiene lugar por la obligación que adquiere la Corporación contratante de ingresar en las cajas del Banco las cantidades que sse obtengan por recaudación de los recursos afectados en garantía de la operación, detallados en el contrato principal.

Dentro de los conceptos afectados, habrá unos de cobro directo por la Corporación, como son los de carnes, bebidas, matadero, etc., los cuales se ingresarán por la misma en el establecimiento bancario que se señale. Para la debida comprobación de los fondos ingresados, el Interventor certificará con referencia a los días quince y último de cada mes y con especificación de conceptos, las cantidades intervenidas que hayan ingresado en la Depositaría procedentes de los recursos que comprende este servicio. 
Los recursos afectados que procedan de liquidaciones practicadas por Hacienda, como los recargos en las contribuciones, usos y consumos, cupos de compensación, etc., los percibirá el Banco directamente y los ingresará en la cuenta del servicio de tesorería, facultándole para ello la Corporación Local por medio de poder, que podrá sustituir en la persona natural o jurídica a quien designe para efectuar los cobros.

De los fondos ingresados podrá disponer la Corporación Local mediante talones suscritos por el Depositario y el Interventor, con el visto bueno del Presidente. Estas disposiciones de fondos, en tanto presente saldo la cuenta, 'serán efectuadas libremente por la Corporación.

Admite la cuenta representativa del servicio de tesorería un descubierto máximo que no podrá exceder de la cantidad que se fije, dentro de la sexta parte del presupuesto ordinario de ingresos. Las órdenes de disposición de fondos en descubierto habrán de cursarse al Banco con un preaviso de cinco días como mínimo.

El Convenio de Tesorería, comprensivo del servicio y de la operación, tendrá de duración el tiempo que tarde la Corporación en reembolsar al Banco de cuanto le adeude, como consecuencia de este contrato y del principal.

\section{Proyectos de contrato: su tramitación.}

En cuanto a las operaciones a largo plazo, únicas que interesan desde el punto de vista de estas cuartillas, las minutas de contrato que formule el Banco de Crédito Local de España se ajustarán a los modelos aprobados por el Ministerio de $\mathrm{Ha}$ cienda en la Orden de $1 .^{\circ}$ de agosto de 1945 . Estos modelos se refieren a operaciones de préstamo y a préstamos con previa apertura de cuenta de crédito. Uno y otro texto de contrato podrán ir precedidos del Convenio Adicional de Tesorería que, como hemos dicho anteriormente, cumple el doble cometido de recoger los recursos que garantizan la operación y conceder anticipos con la limitación de la sexta parte del presupuesto ordinario de ingresos. 
Concedido el crédito y comunicadas a la Corporación las características del mismo, el Banco, previo envío de los documentos solicitados, entre los que se encontrarán, como más importantes, el presupuesto extraordinario y los proyectos de obras; en su caso, procederá a remitirles el correspondiente proyecto de contrato.

Como preliminar a la aprobación del citado proyecto, procederá el informe del Interventor o Secretario-Interventor, según dispone el párrafo 2.: dei artículo 334 del Decreto de 25. de enero de 1946, referente a la Ordenación Provisional de las Haciendas Loicales.

El proyecto de contrato deberá ser aprobado integramente por el Pleno de la Corporación en sesión extraordinaria, requiriéndose, conforme al párrafo $2 .^{\circ}$ del artículo 331 del mencionado Decreto, el voto favorable de las dos terceras partes del número de gestores que de hecho constituyan la Corporación, y, en todo caso, de la mayoria absoluta legal de sus miembros.

Una vez aprobado el proyecto de contrato, se publicará en el "Boletin Oficial" de la provincia un extracto del mismo, anunciándose la exposición al público por término de quince días hábiles del expediente seguido para la contratación con el Banco, conforme a lo dispuesto en el párrafo tercero del citado artículo 331.

Terminado el plazo de exposición y resueltas en su caso las reclamaciones presentadas, el proyecto de contrato deberá elevarse al Ministerio de Hacienda, de acuerdo con lo dispuesto en $\epsilon^{\prime}$ artículo 332, a los efectos de que la operación sea autorizada por dicho Departamento.

El artículo 244 del citado Decreto sobre Ordenación Provisional de las Haciendas Locales, expresa que el expediente de presupuesto extraordinario, con sus anexos y reclamaciones presentadas, deberá elevarse al Ministerio de Hacienda, acompañado de los documentos pertinentes relacionados con la operación de crédito, si se proyectase hacer uso de esta clase de ingresos. Quiere esto decir que uno y otro expediente deberán elevarse a la vez, por lo que, para no perder tiempo inútil- 
mente, deberá hacerse coincidir la aprobación definitiva del presupuesto extraordinario y la del proyecto de contrato.

Es un error, en el que incurren algunas Corporaciones Locales, dar al acuerdo inicial de petición de crédito la solemnidad de adoptarlo en sesión extraordinaria y con el quorum de los dos tercios, porque estos requisitos deberán cumplirse en ia sesión en que se apruebe el proyecto de contrato.

Especificados en otro lugar cuáles son los documentos que deberán enviarse al Ministerio de Hacienda en relación con el presupuesto, conviene ahorà reseñar los que deberán formar el expediente de la operación que, en términos generales, estará constituído por los siguientes:

1. Por el acuerdo inicial de la Corporación, dando estado oficial a la petición de préstamo al Banco.

2. Certificación de la carta del Banco comunicando la concesión del crédito y las características de la operación.

$3^{\circ}$ Otra literal del proyecto de contrato especificando el acuerdo adoptado por la Corporación y el número de asistentea y votantes.

4. "Boletín Oficial" de la provincia en el que se hiz.n pública la exposición del expediente; y

5. Reclamaciones presentadasi o certificación de no haberse interpuesto ninguna.

Juan Grau Marín

Interventor de Fondos de Administración Local y Jefe de la Sección Técnica de Administración Local del Banco de Crédito Local de España. 